\title{
A NOVEL METHOD TO DETERMINE AIR LEAKAGE IN HEAT PUMP CLOTHES DRYERS
}

\author{
Pradeep Bansal ${ }^{*}$, Amar Mohabir and William Miller \\ Building Equipment Group, Energy \& Transportation Science Division \\ Oak Ridge National Laboratory \\ One Bethel Valley Road, MS-6070, Oak Ridge, TN 37831, USA \\ *Email: pban008@gmail.com
}

\begin{abstract}
Although heat pump clothes dryers offer the potential to save a significant amount of energy as compared to conventional vented electric dryers; they are prone to air leakage that can limit their efficiency gain. This study serves to develop a novel method of quantifying leakage, and to determine specific leakage locations in the dryer drum and air circulation system. The method follows an American Society of Testing and Materials (ASTM) standard, which is used to determine air leakage area in a household ventilation system through fan pressurization. This ASTM method is adapted to the dryer system, and the leakage area is determined by an analysis of the leakage volumetric flow - pressure relationship. The procedure presents a framework that determines and quantifies major components contributing to leakage in HPCDs. The novel method can improve component design features, resulting in more efficient HPCD systems.
\end{abstract}

Key words: Heat pump clothes dryer, HPCD, efficiency, air leakage, vented dryer.

\section{Nomenclature}

$Q: \quad$ Leakage volumetric flow rate, $\left[\frac{m^{3}}{s}\right]$

$C: \quad$ Air leakage coefficient, $\left[\frac{m^{3}}{s * P a^{n}}\right]$

$A_{o}$ : Outlet orifice cross sectional area, $\left[\mathrm{m}^{2}\right]$

$K: \quad$ Orifice outlet to inlet cross sectional area

$P^{*}: \quad$ Test pressure, $[P a]$
$\Delta P: \quad$ Pressure gradient from drum to ambient, $[\mathrm{Pa}]$

$n: \quad$ Pressure exponent

ELA: Effective leakage area, $\left[\mathrm{m}^{2}\right]$

$\rho: \quad$ Air density at the leakage point $\left(70^{\circ} \mathrm{C}\right.$, $70 \%$ relative humidity), $\left[\frac{\mathrm{kg}}{\mathrm{m}^{3}}\right]$

HPCD: Heat pump clothes dryer

This manuscript has been authored by UT-Battelle, LLC under Contract No. DE-AC05-00OR22725 with the U.S. Department of Energy. The United States Government retains and the publisher, by accepting the article for publication, acknowledges that the United States Government retains a non-exclusive, paid-up, irrevocable, world-wide license to publish or reproduce the published form of this manuscript, or allow others to do so, for United States Government purposes. The Department of Energy will provide public access to these results of federally sponsored research in accordance with the DOE Public Access Plan (http://energy.gov/downloads/doe-public-access-plan). 


\section{INTRODUCTION}

Heating of air is an expensive process that uses primary energy in all types of clothes dryers. The majority of clothes dryers (about 80\%) in U. S. households are vented electric dryers

34 [1], where air flows in an open cycle. The air undergoes three specific cycles- (i) air is heated by 35 an electric heater, (ii) air enters the clothes drum absorbing moisture from wet clothes, and (iii) the hot moist air is exhausted outdoors by a fan from the dryer. This results in about $40 \%$ of the

37 applied heat being wasted in the form of an elevated exhaust temperature [2]. In a heat pump clothes dryer (HPCD), shown in Figure 1, the air is circulated in a closed loop without the need of any exhaust ducting and most of the heat is retained inside the cycle.

The vapor compression heat pump cycle of a HPCD consists of four main componentsan evaporator, a compressor, a condenser and an expansion valve. The air duct houses the

42 evaporator and condenser of the refrigeration cycle (see Figure 1). The cycle operates in a closed loop where moist air from the drum flows in the air duct over the evaporator, where it is

44 dehumidified. The resultant condensed water at the evaporator is collected in a pan which is 45 drained at five-minute intervals by a pump. The dehumidified air then flows over the condenser of the heat pump cycle, where it is sensibly heated and flows back into the dryer drum to

47 complete the cycle. Due to the recycling of heated air, a heat pump clothes dryer offers the potential to save $60 \%$ of energy as compared with the conventional vented electric dryers [3].

Although heat pump clothes dryers offer higher energy efficiency through air recirculation, it is likely that various components are prone to air leakage (of up to $40 \%$ of the 51 total air volumetric flow [2]), resulting in a loss of efficiency. Stawreberg et al. [4] noted that 52 there is considerable leakage through the gap between the heater and the drum inlet and between 53 the heat exchanger and the heater in a condensing tumbler dryer. Bansal et al. [5] assumed 
54 upwards of $20 \%$ leakage of the total air volumetric flow in their modeling studies. An easy way

55 to maximize the energy efficiency of a HPCD is to make the air circulation system relatively 56 leak-tight. Leakage points may be created through manufacturing defects or damaged

57 components and are expected to be scattered in parts of both the drum and air circulation duct of

59 the leakage aspect of specific parts of the dryer has never been studied in detail previously. So

60 far, efforts have primarily focused on analyzing the energy efficiency of HPCDs [5, 11, 13, 15,

61 16], while only the overall leakage has been documented in one study [2]. Knowledge of specific

62 leakage points offers the necessary information to minimize the amount of leakage in the air

63 cycle, providing information for the best design possible. Hence this study serves to develop a

64 novel method for quantifying leakage from HPCDs, and subsequently, tests this method on 65 easily accessible specific leakage locations in the dryer drum and air circulation system.

\section{AIR LEAKAGE TEST PROCEDURE}

67 The basis of the proposed clothes dryer air leakage test method is the American Society of Testing and Materials (ASTM) standard E779 - 10 that allows determining the air leakage area in a household ventilation system through fan pressurization [20]. This ASTM method is

70 readily adaptable to the dryer system because the leakage measurement process is the same as a

71 ventilation system. The dryer system is pressurized just as a ventilation system, and flow rates

72 are measured to determine leakage. The leakage area is determined following the leakage

73 volumetric flow and pressure relationship provided in E779-10 [21]. A Minneapolis Duct Blaster

74 [22] is used to pressurize the dryer drum and an accompanying pressure and flow gauge (DG -

75 700) is used to measure the duct blaster air flow rate and drum pressure drop. The DG - 700 is a 
calibrated sensor from the same manufacturer that measures the Minneapolis Duct Blaster's flow

77 rate from the pressure drop along the fan. The information on measurement uncertainties is

78 presented in section 3. The duct blaster pressurizes the dryer drum. A pressure tap is fed to the

79 dryer drum, and the DG - 700 records the pressure caused by the duct blaster in that region.

80 Successful verification and implementation of this method allows determination and

81 quantification of leakage points in the dryer system, further providing grounds for extension to

82 other air leakage scenarios.

Figure 1 displays a schematic of the HPCD showing its components and various leakage points. There are two general areas of leakage, the dryer drum and the air circulation duct. The components of the drum that contribute greatest to its leakage are the front rotation crease, and the back rotation crease. Both of these parts allow the drum to rotate, and must have the proper

87 spacing to do so. Hence it is likely that these parts are the largest contributors to air leakage in the drum. There are three different types of baffles along the drum of the dryer, all of which are accessible for sealing. There are small creases exposed on all baffles. The baffle filter has a removable filter, thus, has the likelihood of leakage. The wavy baffle and oval baffles are shaped

91 as they are named, but do not have any filters attached to them. Their function is to add extra

92 tumbling on clothes during the dryer cycle. The air circulation duct is not easily accessible;

93 however the parts that have been observed to lead to its leakage are the front grill, back grill, and 94 air filter. The front and back grill of the dryer connect the air flow from the air circulation duct to 95 the dryer drum. 
ASTM Standard E779-10 uses the following correlation to relate the leakage volumetric flow rate and driving pressure:

$$
Q=C(\Delta P)^{n}
$$

104 volumetric flow data points. used to estimate the HPCD leakage:

$$
Q=K A_{o} \sqrt{\frac{2 \Delta P}{\rho}}
$$

111

Equation (2) is the orifice equation derived from Bernoulli's principle of flow along a streamline, neglecting changes in potential energy. Combining Equations (1) and (2) yields Equation (3) for calculating the effective leakage area (ELA) of all points:

$$
A_{o}=E L A=\frac{C \Delta P^{\left(n-\frac{1}{2}\right)}\left(\frac{\rho}{2}\right)^{\frac{1}{2}}}{K}
$$

115 Note that the ASTM standard assumes that all orifice lengths are negligible, thus the value of $K$ 116 is $1^{1}$. Furthermore, adapting Equation (3) to the dryer system requires the following assumptions:

\footnotetext{
${ }^{1}$ Effective leakage area, ELA, used herein is documented in ASTM E 1827, the formulation in Eq 3 differs from a similar measure of airtightness that uses the same reference pressure but assumes a discharge coefficient [23].
} 
- The dryer drum and air circulation system leaks are similar to those of a household ventilation system.

- During steady state operation, the leakage volumetric flow rate equals the inlet fan flow rate.

- The driving force for leakage is the pressure difference between the drum pressure and the ambient pressure.

A major difference between a dryer air circulation system and a household ventilation system is size - the dryer circulation system is much smaller. In both cases, the points at which air leakage occurs are small defects which can be approximated as orifices. The phenomenon of leakage in both cases is therefore identical, justifying the use of Equation (1) and (2) in the dryer system. During steady state operation, the only points of air flow in the system are the inlet fan pressurization, and the outlet leakage. Thus by conservation of mass, the volumetric flow rate at the fan inlet must be equal to the combined leakage volumetric flow rate of all leakage points of the HPCD. The drum and air circulation system pressure is uniform once pressurized by the fan after achieving steady state, and the only other pressure region is the ambient pressure. Therefore this pressure gradient provides the driving force for the leakage or air.

The DG - 700 gauge used to measure the volumetric flow rate and drum pressure drop determines the effective leakage area at a reference pressure of $50 \mathrm{~Pa}$ based on the following empirical correlation given in the DG - 700 manual $[20,21]$ :

$$
E L A=\frac{Q\left(\frac{50}{P^{*}}\right)^{0.65}}{7.495}
$$



pressure, $P^{*}$, is $50 \mathrm{~Pa}$ [21]. The value of $Q$ is obtained from the same ASTM correlation in

140 Equation (1), and the values of $C$ and $n$ are fixed to 6.26 and 0.5 respectively, as specified in the 141 Duct Blaster manual [20]. At a $\pm 5 \mathrm{~Pa}$ range from the ideal test pressure of $50 \mathrm{~Pa}$, the uncertainty 142 on the DG-700 gauge is at most $1 \%$ in $n$ [21]. Table 1 displays uncertainties for a range of $n$ corresponding to different test pressures [21]. The effect of this is very small on the volumetric

144 flow rate and is assumed to be negligible. The DG - 700 device assumes a $K$ value of 0.61 (for 145 building operations), which was corrected to a $K$ value of 1 for application to the HPCD. A comparison will be made from the effective leakage area using Equations (3) and (4).

Table 1: DG - 700 Uncertainties in $n$ as a Function of $P^{*}$ for the 50 Pa Mode

\section{METHODS}

The experimental set up primarily consisted of three main components, namely a Minneapolis Duct Blaster fan, a flexible extension duct, and the HPCD. All of these components were connected in series as shown in Figure 2. Figure 3 shows a photograph of the actual layout of the leakage measurement apparatus and the HPCD prototype. The flexible extension duct is an airtight aluminum duct connecting the duct blaster fan to the dryer drum by attachment through a metal fitting bolted onto the drum door. The accompanying DG - 700 gauge, also provided by the manufacturer of the duct blaster, is used to measure the fan volumetric flow rate while simultaneously measuring the drum pressure drop. An outline of the measurement principle was presented in section 2. The duct blaster incorporates a variable speed fan [20], which has three inlet rings of varying inner diameter that attach to its inlet to provide a range of volumetric flow rate and related pressure drops. The ring of the smallest diameter (ring 3) was most suitable for 
161 our application since it provided pressure drops that were in the fan's calibration region, and 162 closest to the operating pressure of the HPCD.

163

164

165

166

167

168

169

170

171

172

173

174

175

176

177 178 calculate an effective leak area.

179

180

181

182

183

184

The two regions where the pressure was measured included the fan inlet and the dryer drum. A static pressure tap was installed in the drum. Both pressure measurement regions were connected to the DG - 700 gauge using plastic tubing. Both channels are referenced to ambient pressure. The fan volumetric flow rate was controlled by a variable speed fan controller.

\section{Figure 2: Schematic of experimental setup}

Figure 3: Layout of the air leakage test apparatus for the HPCD prototype

The independent variable measured by the leakage test apparatus is the pressure drop between the drum and the ambient. Accordingly, the fan was controlled to pressurize the drum from 30 to $120 \mathrm{~Pa}$ for all sealed configurations. Data was recorded for seven different pressure drops from which the leakage volumetric flow rate was reduced and recorded. The data was subsequently plotted and a power regression was performed for each sealed configuration to

The approach used to determine the leakage from various points within the HPCD began with fully sealing all the components. This provided the baseline leakage or miscellaneous losses. Following this, each component was unsealed individually to determine its contribution to leakage. The fully unsealed case gives the leakage of the dryer as it comes out of the manufacturer. During initial testing, it was determined that the contribution of baffles to leakage was insignificant, therefore they were not considered in the air leakage analysis. The five 
185 components that were sealed are shown in Figure 1, namely the front and back rotation crease, 186 the front and back grill and the air filter.

187 The first set of leakage flow rate vs. pressure drop data was for a fully "sealed - least 188 leak" configuration of the dryer, and this was used as a benchmark for comparison to all other 189 sealed configurations, with one exception - the air filter. The air filter is connected to the air 190 circulation duct; if the front and back grill are sealed, air cannot flow through the air filter. With 191 the exception of the air filter, each of these components was unsealed individually. The 192 difference between the increased leakage area corresponding to unsealed configurations (i.e. 193 unsealing the front crease only, the back crease only, the front grill only, and the back grill only) 194 and the baseline fully "sealed - least leak" leakage area yields the individual contribution of that 195 component to leakage. The difference in leakage area corresponding to unsealing the air filter 196 and the leakage area corresponding to unsealing the front and back grills is the contribution 197 associated with the air filter.

\section{RESULTS AND DISCUSSION}

Prior to sealing components, it was observed that rotating the dryer drum led to different leakage volumetric flow rates for the same drum pressures. The wavy baffle in the dryer drum

201 was assigned a value of 0 degrees at an arbitrary initial position and was rotated through 90, 180 202 and 270 degrees. Unsealed leakage tests were performed at each of these rotations. A volume 203 flow rate vs. pressure curve was generated for each of these rotations and these curves are given 204 in Figure 4. Though the cause of this discrepancy is not fully known, it is attributed to 205 manufacturing defects and wear of the dryer over time. The dryer has been extensively tested 
during the last few years and hence it is likely that this may have caused some internal damage. Since the 270 degree rotation yielded the largest flow, all tests were performed at that rotation. The current method of analyzing each component individually and comparing them to the same baseline minimizes sensitivity and error issues, and also allows the determination of all component leakage separately. It has also been verified that the front and back grill do not contribute to drum leakage, but they are responsible for duct leakage. The best "sealed leastleak" scenario may be referred to as the "miscellaneous losses". Only one of the mentioned components was unsealed at a time to isolate their leakage area contribution. However, the air filter is an exception due to the fact that the duct system (the front and back grill) must be open to allow air flow through the filter. In this case, the air filter leakage was compared with the front and the back grill leakage that results in the air filter leakage. The drum components were unsealed first, followed by the air filter.

Figure 4: Leakage flow rate $\left(\frac{m^{3}}{s}\right)$ vs. $\Delta P$ - Unsealed leakage corresponding to various drum rotation angles

Figure 5 shows the results of the leakage volumetric flow rate vs. pressure drop tests. The trends generally follow as expected - the unsealed configuration curve is located above all other curves, and the fully sealed configuration curve lies below all curves. One notable observation is the leakage curve for the front grill did not change after additionally unsealing the back grill. This supports the claim that the front and back grill connect to the same leakage points. In either configuration, air flows to the same leakage points in the air circulation duct, and the actual leakage area is not affected. Another observation is, even when all components are fully sealed, there is still some leakage reported. There are regions outside the drum where air flow can be felt, however, they are deep inside the dryer housing and cannot be accessed unless the housing 
228 is taken apart. It is currently unknown where these leakage points are located. However, it is very 229 likely that the leakage is from the drum and not the air circulation duct because air flow is cut off 230 to the duct when the front and back grill are sealed.

247 comparison with other cases. device, are given in Table 2. The best "sealed - least leak" case scenario yielded an effective leakage area of $0.0010 \mathrm{~m}^{2}$, and this leakage is associated with the drum. Unsealing the front rotation crease (2) increased the area to $0.0014 \mathrm{~m}^{2}$, whereas unsealing the back rotation crease (3) increased the area to $0.0021 \mathrm{~m}^{2}$. Unsealing only the front grill (5) only increased the area to $0.0015 \mathrm{~m}^{2}$, and there was no change when additionally unsealing the back grill (6). Unsealing the air filter (7) was followed by an increase in leakage area to $0.0020 \mathrm{~m}^{2}$. These results suggest that drum leakage is greater than the duct leakage. Finally, as noted earlier, the $K$ values were corrected to 1 for leakage areas measured with the DG-700. This correction results in effective leakage areas that are in close agreement as calculated with Equation (3) and measured with the DG-700. Figure 6 displays these results graphically, where the horizontal solid 'red' line across 
254 Five independent leakage locations were isolated from these results, which include: the front and 255 back rotation crease, the front grill/duct, the air filter, and the remainder of the drum 256 (components 2, 3, 5, 7 and 8 respectively, illustrated in Figure 1). The leakage area and the 257 percentage of total leakage area for these five components are given in Table 3 . The calculated 258 areas from Equation (3) were used to calculate these differences and percentages.

Comparing values from Tables 2 and 3, a discrepancy can be noted between the total 264 leakage and the fully unsealed leakage. Table 2 displays a measured value of $0.0032 \mathrm{~m}^{2}$ 265 (configuration 1), while summing up all individual component leakages in Table 3 results in a 266 value of $0.0034 \mathrm{~m}^{2}$, a $6 \%$ deviation from the former. As mentioned in the theory section, the 267 uncertainties using a test pressure of $50 \mathrm{~Pa}$ does not significantly affect the measured values. 268 Thus cause of this discrepancy is likely to be the non-linear nature of the pressure volume 269 correlation. 275 the front and back crease. 

unknown. According to Table 1, the worst error on the pressure exponent is on the order of $20 \%$, which comes from a test pressure of $10 \mathrm{~Pa}$. Applying this to all of these parts (including the fully 282 unsealed configuration which is used in calculating individual leakage comparisons) yields the 283 following ranges: $0.0002-0.0004,0.0007-0.0014,0.0008-0.0019$ for the front crease, back 284 crease and combined two respectively. In actual measurements however, variation in the pressure 285 exponent will be at most $1 \%$ which does not affect these values. Therefore the discrepancy here cannot be attributed to uncertainty, and a further investigation would be needed to determine the 287 coupling of leakage on these components.

This method determines large leakage points, but is limited in determining specific parts, 289 especially when the leakage differences are small. The process of sealing could be more robust; 290 in this experiment sealing was done by taping openings with duct tape. An alternative is to build 291 panels for each component that can quickly connect and disconnect. Further, the next step would 292 be to analyze leakage components that are not easily accessible.

293 It is concerning that there is still leakage observed in the fully sealed case, and mitigating 294 these leaks are unavoidable with this current method of sealing, which suggests problems in the 295 manufacturing process. By observation of a change in the leakage area measurement, the 296 controllable leak regions thus far are the front and back rotation crease, the air filter and the front 297 grill. It is difficult to quantify any leakages in the duct system without taking apart the dryer. 298 This suggests that there is room for the manufacturing process to create a more leak tight air duct 299 system. 
Though the experiments were performed in steady state flow, the startup and cooling 301 down period of a dryer cycle were not steady. If there is significant leakage in the HPCD, it is

302 likely that repeatedly heating and cooling regions of leakage could affect leakage area due to 303 constant agitation of that region. Unfortunately, this method can only be implemented on a dryer 304 when it is not in operation, and thus cannot directly measure the effect of leakage during a 305 transient process. Nonetheless, even if the effective leakage area (ELA) is not the actual value, it 306 is a reasonable estimate on proportional decrease as a result of sealing components, due to 307 repeatability, thus the most reliable parts of the experiment are percentage leakage contribution 308 for various configurations.

\section{CONCLUSIONS}

This paper presents a novel method to determine air leakage in HPCDs that repeatedly 311 displays a decrease in effective leakage area after sealing various dryer components. The 312 research presents a framework to detect and quantify air leakage in a HPCD system, and, in 313 general can be applied to any system that contains air leakage through defects that are 314 approximately orifices, so long as the pressure gradient driving the leakage can be measured. The 315 leakage coefficients for Equation (3) vary for each configuration and are always constant for 316 Equation (4). The worst comparison between the predicted leakage area and the measured area is 317 within margin of 7\%. This supports extension of the ASTM E779 - 10 method to dryer leakage 318 testing and can be used to determine, at the least, relative leakage. Easily accessible leakage 319 points were quantified: the front and back crease, the leakage in the duct, the air filter, and the 320 remaining leakage in the drum. The concordance of results indicates that our method estimates 321 the leakage area reasonably well. 


\section{ACKNOWLEDGMENTS}

The authors are thankful to the Building Technologies Office of the US Department of Energy for their financial support and industry partner General Electric Appliances for their inkind and technical support. Special thanks are due to a number of contributors for their invaluable contributions and support during this project, including Mr. Edward Vineyard, Dr. Bo Shen, Dr. Kyle Gluesenkamp, Dr. Keith Rice, Mr. Van Baxter, Mr. Phillip Boudreaux, Mr. Jerry Atchley, Mr. Randall Linkous, Mr. Neal Durfee, Mr. David Beers, Mr. Zhiquan Yu and Quentin Pollett.

\section{[1] US Department of Energy (DOE) Buildings Energy Data Book - Residential Sector Energy} Consumption, 2010, http://buildingsdatabook.eren.doe.gov/TableView.aspx?table=2.1.5

[2] Beers, D. Development of heat pump clothes dryers, Private Communication, 2014.

[3] Pescatore, P. and Carbone, P., High efficiency, high performance clothes dryer, TIAX Report No. D0040, March 31, 2005.

[4] Strawreberg, L., Berghel, J. and Renstrom, R., Energy losses by air leakage in condensing tumbler dryers. Applied Thermal Engineering, 37, pp 373-379, 2012.

[5] Bansal, P. K., Braun, J., and Groll, E., Improving the energy efficiency of conventional tumbler clothes drying systems, International Journal of Energy Research, 25 (15), pp 1315-1332, 2001.

[6] Ameen A. and Bari S., Investigation into the effectiveness of heat pump assisted clothes dryer for humid tropics, Energy Conversion and Management. 45(9-10): 1397-1405, 2004.

[7] Bansal, P K, Sharma, K., and Islam, S., Thermal analysis of a new concept in a household clothes tumble dryer, Applied Energy, 87, pp 1562-1571, 2010.

[8] Bansal, P K., Islam, S., and Sharma, K., A novel design of a household tumbler dryer, 30, Applied Thermal Engineering, pp 277-285, 2010.

[9] Bassily, A.M. and Colver, G.M., Performance Analysis of an Electric Clothes Dryer, Drying Technology, 21 (3), pp 500-524, 2003.

[10] Beers, D.G., Hensley, A.L. and Okruch, N., Apparatus and Method For Dry Cycle Completion Control in Heat Pump Dryer By Declining Capacity Indication By Rolling Average Compressor Watts Or Heat Exchanger Pressure Or Temperature, Patent No.: US20120017615 A1, 2010.

[11] Braun, J., Bansal, P. K., and Groll, E., Energy efficiency analysis of air cycle heat pump dryers, International Journal of Refrigeration, 25 (7), pp 954-965, 2002.

[12] Chua, K.J. and Chou, S.K., A modular approach to study the performance of a two-stage heat pump system for drying, Applied Thermal Engineering, 25(8-9), pp 1363-1379, 2005. 
[13] Conde, M.R. Energy Conservation with Tumbler Drying in Laundries, Applied Thermal Engineering, 17 (12), pp 1163-1172, 1997.

[14] Do, Y., Kim, M., Kim, T., Jeong, S., Park, S., Woo, S., Kwon, Y., Jung, Y., Lee, J. and Ahn Y., An experimental study on the performance of a condensing tumbler dryer with an air-toair heat exchanger, Korean Journal of Chemical Engineering, 30(6), pp 1195-1200, 2013.

[15] Huelsz, G., Urbiola-Soto, L., López-Alquicira, F., Rechtman, R. and Hernández-Cruz, G., Total Energy Balance Method for Venting Electric Clothes Dryers, Drying Technology, 31(5), pp 576-586, 2013.

[16] Hustvedt, G., Review of laundry energy efficiency studies conducted by the US Department of Energy. International Journal of Consumer Studies, 35(2), pp 228-236, 2011.

[17] Lambert, A. and Spruit, F. and Claus, J., Modelling as a tool for evaluating the effects of energy saving measures- case study: a tumbler dryer, Applied Energy, 38, pp 33-47, 1991.

[18] Minea, V., Heat-Pump-Assisted Drying: Recent Technological Advances and R\&D Needs, Drying Technology, 31(10), pp 1177-1189, 2013.

[19] Rezk, K. and Forsberg, J., Geometry development of the internal duct system of a heat pump tumble dryer based on fluid mechanic parameters from a CFD software, Applied Energy, 88(5), pp 1596-1605, 2011.

[20] American Society for Testing and Materials. "Standard Test Method for Determining Air Leakage Rate by Fan Pressurization,” ASTM International, Designation: ASTM E779 - 10, 2011.

[21] The Energy Conservatory. "Minneapolis Duct Blaster ${ }^{\circledR}$ Operation Manual," http://dev.energyconservatory.com/wp-content/uploads/2014/07/Duct-Blaster-Manual-Series-B-DG700.pdf, 2012.

[22] The Energy Conservatory. "Operating instructions for the DG - 700 Pressure and Flow Gauge," Diagnostic Tools to Measure Building Performance, http://www.energyconservatory.com/sites/default/files/software/dg700simulatorman.pdf, 2009.

[23] CGSB, Determination of the Airtightness of Building Envelopes by the Fan Depressurization Method, National Standard of Canada, CAN/CGSB-149.10-M86, Canadian General Standards Board, Ottawa, 1986. 
391

392 393

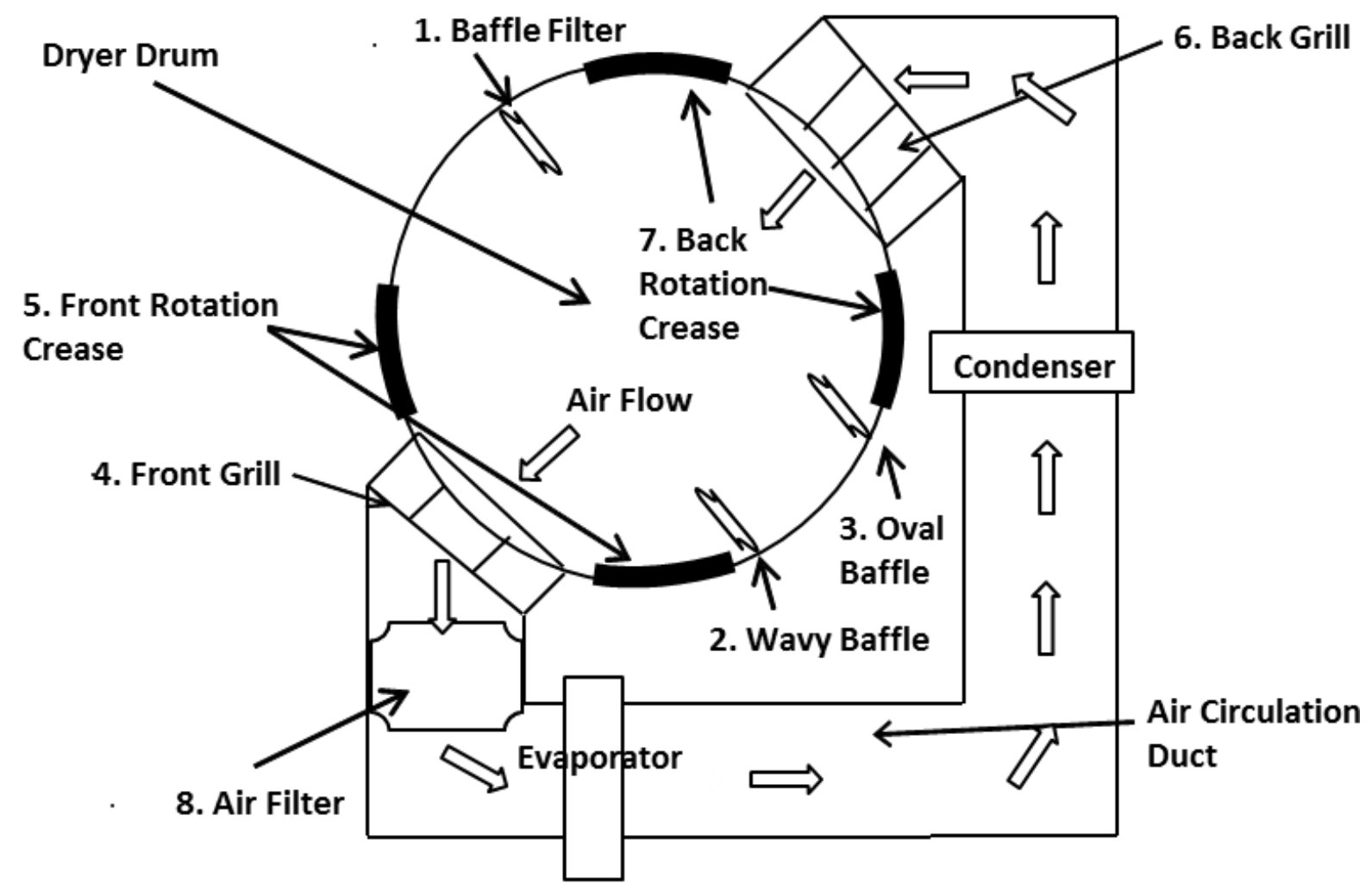

Figure 1: Schematic of heat pump clothes dryer (HPCD) and locations for air leakage

\begin{abstract}
Duct Blaster
\end{abstract}

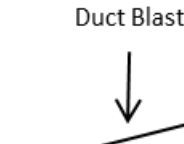

Flexible Extension Duct

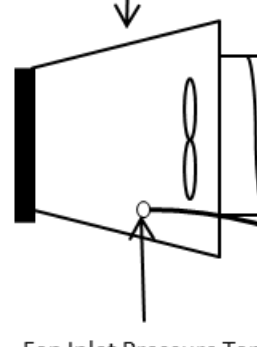

Fan Inlet Pressure Tap<smiles>C=[V]</smiles>

$\downarrow$

Metal Fitting

$\downarrow$

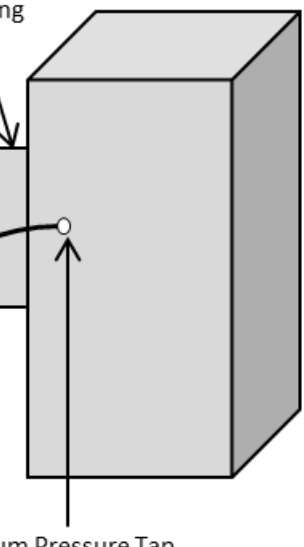

Drum Pressure Tap

Figure 2: Schematic of experimental setup 


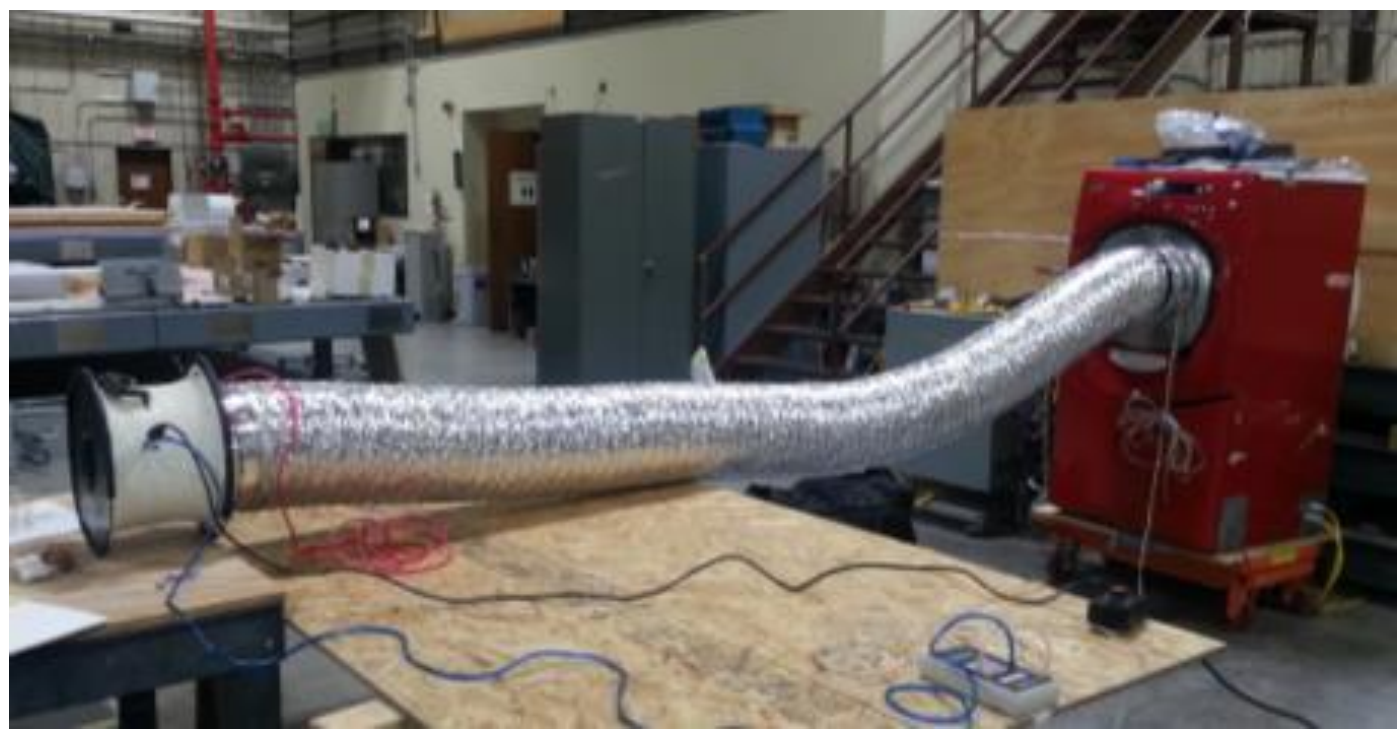

Figure 3: Layout of the air leakage test apparatus for the HPCD prototype

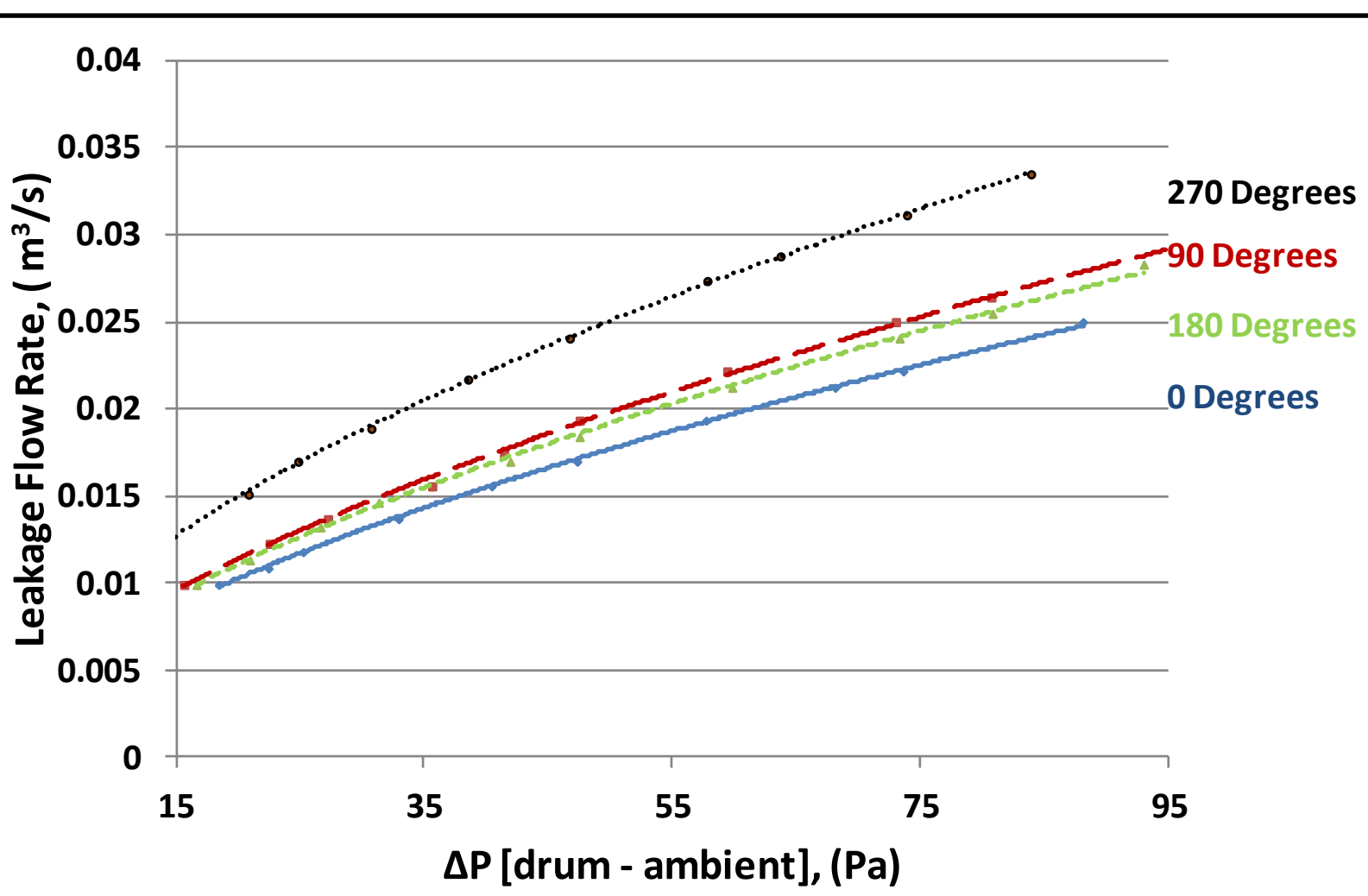




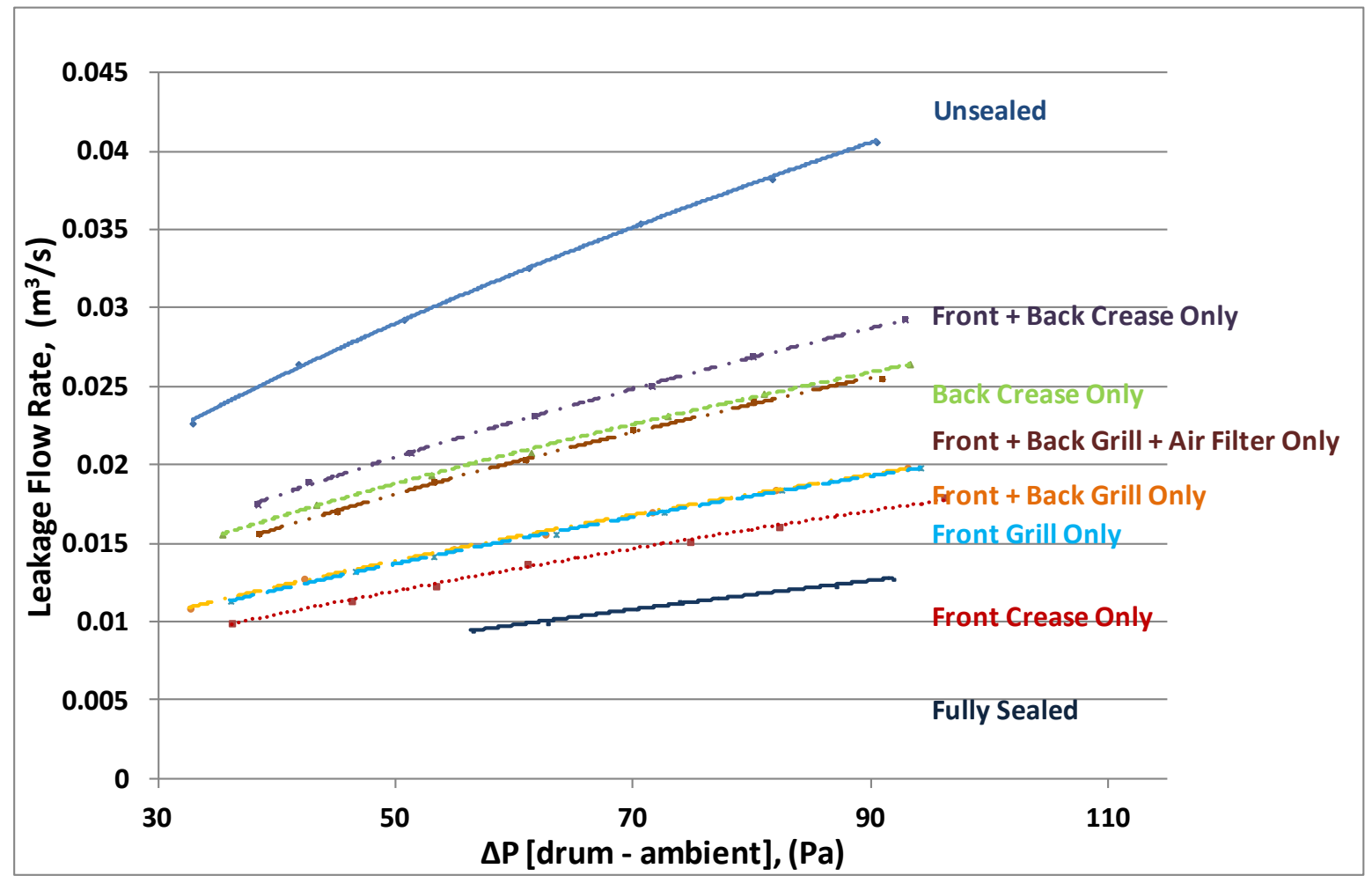

Figure 5: Leakage volumetric flow rate $\left(\frac{\mathrm{m}^{3}}{\mathrm{~s}}\right)$ vs. drum pressure drop $(\mathrm{Pa})$ for sealing of various HPCD components.

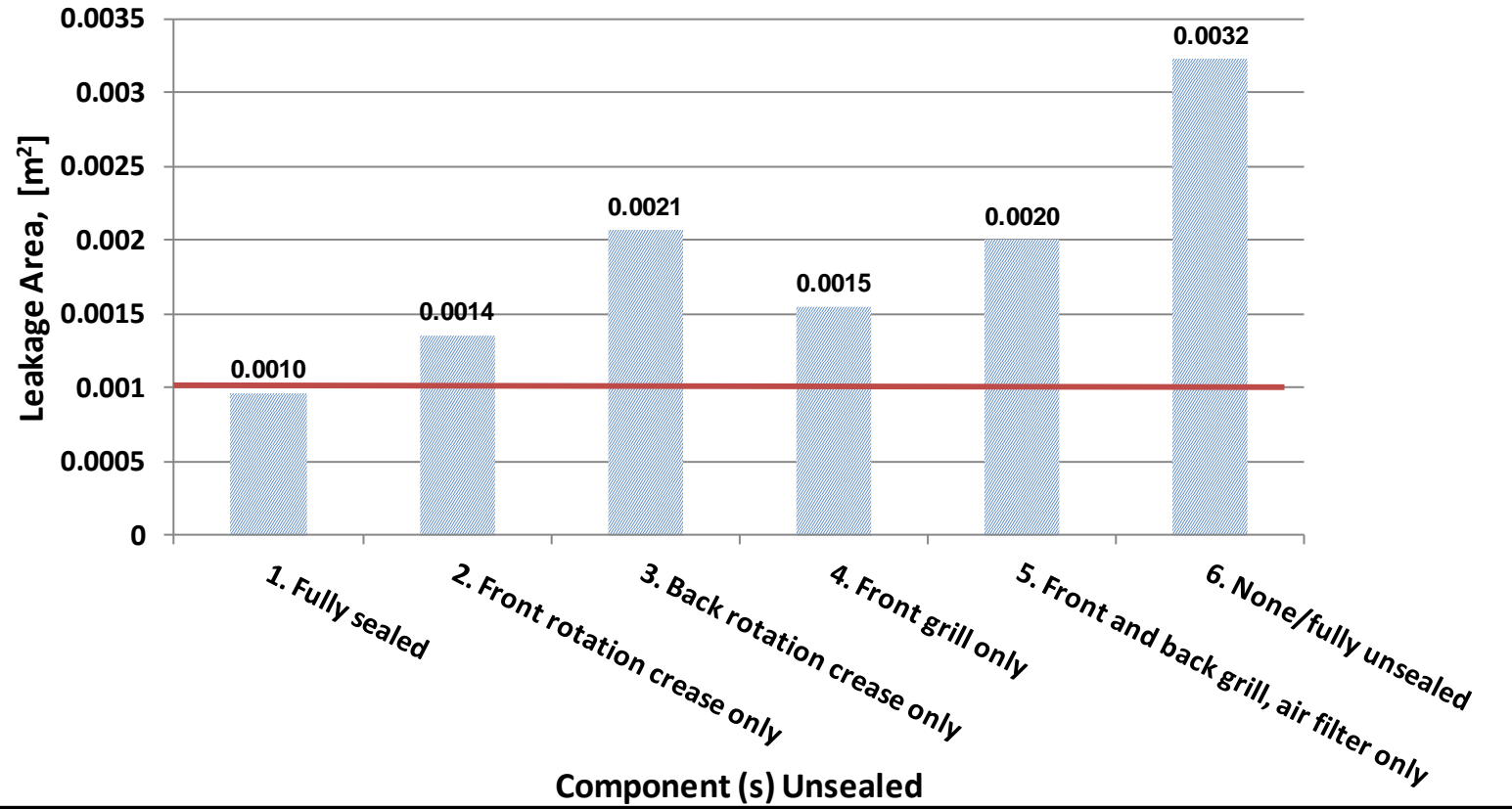


Figure 6: Leakage area attributed to various HPCD components.

Table 1: DG - 700 Uncertainties in $n$ as a Function of $P^{*}$ for the $50 \mathrm{~Pa}$ Mode

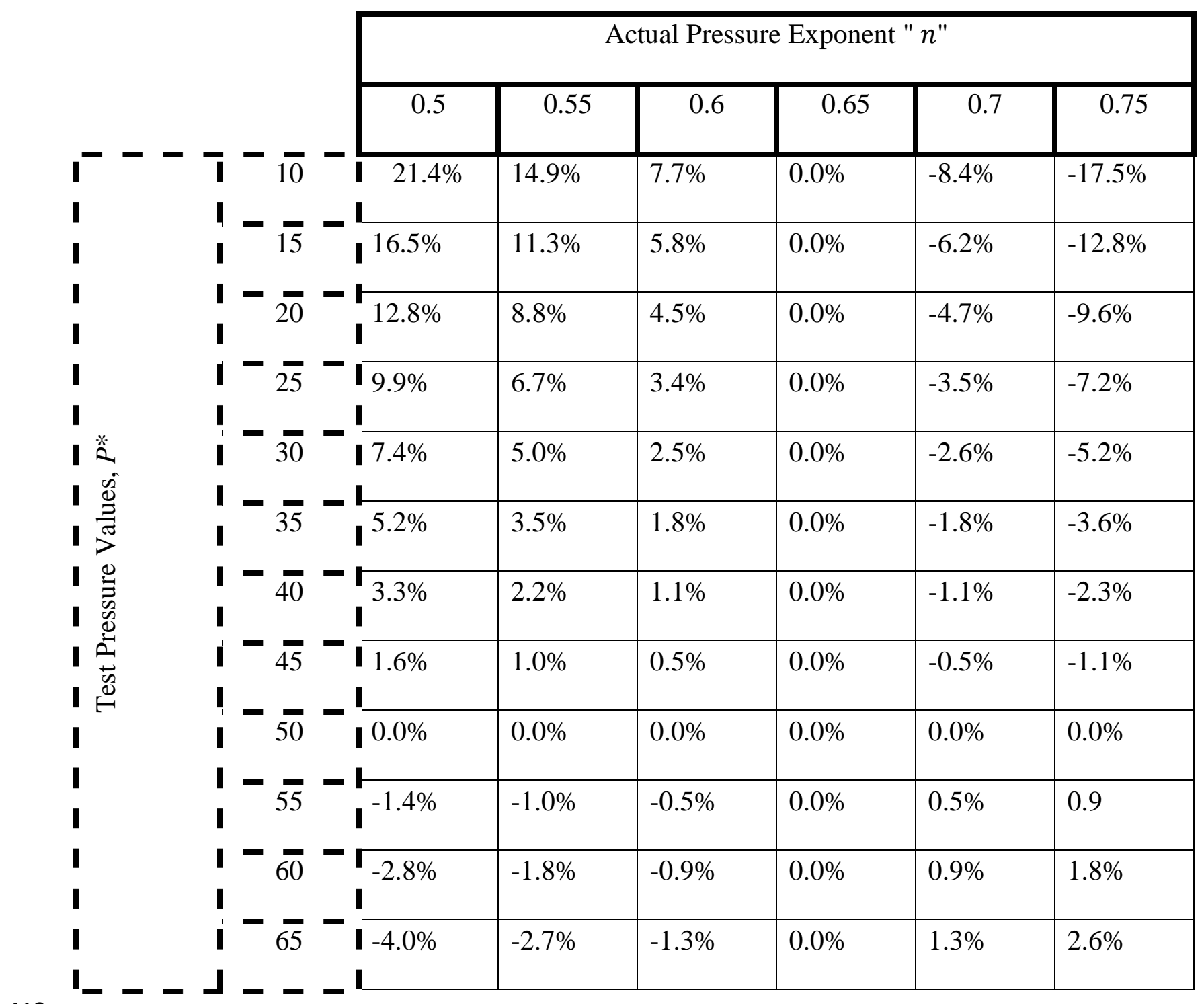


Table 2: Regression Coefficients and Effective Leakage Areas

\begin{tabular}{|l|l|l|l|l|}
\hline Parts Unsealed & $\mathrm{c}$ & $\mathrm{n}$ & $\begin{array}{l}\text { Calculated } \\
\text { area, Eq. 3, } \\
{\left[\mathrm{m}^{2}\right], 50 \mathrm{~Pa}}\end{array}$ & $\begin{array}{l}\text { Measured area, } \\
\mathrm{Pa}\end{array}$ \\
\hline 1. Fully sealed $\left[\mathrm{m}^{2}, 50\right.$ \\
\hline 2. Front rotation crease only & 0.0011 & 0.605 & 0.0013 & 0.0014 \\
\hline 3. Back rotation crease only & 0.0022 & 0.5453 & 0.0020 & 0.0021 \\
\hline 4. Front and back crease only & 0.0022 & 0.575 & 0.0023 & 0.0023 \\
\hline 5. Front grill only & 0.0014 & 0.5823 & 0.0015 & 0.0015 \\
\hline 6. Front and back grill only & 0.0015 & 0.5685 & 0.0015 & 0.0015 \\
\hline $\begin{array}{l}\text { 7. Front and back grill, air filter } \\
\text { only }\end{array}$ & 0.0018 & 0.5836 & 0.0019 & 0.0020 \\
\hline 8. None/fully unsealed & & & 0.0269 & 0.0010 \\
\hline
\end{tabular}

Table 3: Individual Component Leakage

\begin{tabular}{|l|l|l|}
\hline Point of Leakage & Leakage Area $\left[\mathrm{m}^{2}\right]$ & Percentage of total Leakage \\
\hline Miscellaneous/ Drum & 0.0010 & 28 \\
\hline Front rotation crease & 0.0004 & 11 \\
\hline Back rotation crease & 0.0011 & 31 \\
\hline Front grill/Duct & 0.0005 & 17 \\
\hline Air Filter & 0.0005 & 13 \\
\hline Total & 0.0034 & 100 \\
\hline
\end{tabular}

420 
Table 4: Leakage Areas for Configurations 2, 3 and 4

\begin{tabular}{|l|l|}
\hline Components Unsealed & Leakage Area $\left[\mathrm{m}^{2}\right]$ \\
\hline Front rotation crease & 0.0004 \\
\hline Back rotation crease & 0.0011 \\
\hline Front and back together & 0.0013 \\
\hline
\end{tabular}

424 